\title{
To Make the Water Safer
}

\author{
Peiyue $\mathrm{Li}^{1,2,3}$
}

Received: 24 June 2020 / Revised: 24 June 2020 / Accepted: 3 July 2020 / Published online: 9 July 2020

(c) Springer Nature B.V. 2020

\begin{abstract}
Water quality affects human health and ecological biodiversity, as water ingestion is the primary exposure pathway of human health risk, and water is the most active natural element participating in the transformation of ecological system. In this paper, the background of editing this special issue was outlined, and the main contents and contributions of papers published in this special issue were introduced. Several research directions that are important to guarantee the water safety in the Yellow River basin were proposed. This special issue provides a platform for researchers to share their latest research results, which will not only be helpful for enhancing water protection and management in the Yellow River basin, but also benefit the international community in addressing similar issues.
\end{abstract}

Keywords Water resources $\cdot$ Water pollution $\cdot$ Health risk $\cdot$ Ecological environment $\cdot$ Drinking water quality

\section{Introduction}

Water is one of the most significant fundamental resources to mankind. With the continuous development of the society, it becomes more and more important due to the increasing demand of it. However, water is in shortage considering its uneven spatial and temporal distributions across the globe (Oki and Kanae 2006). The water shortage crisis is further stressed by the climate change and the water contamination of human activities. It is even regarded by some researchers as the potential cause of wars (Chellaney 2013; Lowe and Silvester 2014; Han et al. 2016). The important role of water in natural processes and social revolution should not be underestimated, because its quality significantly affects the human health and social stability (Li and Wu 2019a, b).

The Chinese Loess Plateau is one of the most droughtstricken areas. Like many other arid and semi-arid regions

Peiyue Li

lipy2@163.com; peiyueli@chd.edu.cn

1 School of Water and Environment, Chang' an University, No. 126 Yanta Road, Xi' an 710054, Shaanxi, China

2 Key Laboratory of Subsurface Hydrology and Ecological Effects in Arid Region of the Ministry of Education, Chang' an University, No. 126 Yanta Road, Xi' an 710054, Shaanxi, China

3 School of Water Resources and Environment, Hebei GEO University, No. 136 East Huai' an Road, Shijiazhuang 050031, Hebei, China of the world, the Chinese Loess Plateau is in short of water resources for drinking and other usages due to limited rainfall, although the second largest river of China, the Yellow River runs across this area. It is the most serious region with severe soil erosion and water issues that have drawn much attention from researchers (He and Wu 2019a, b; He et al. 2019; Li et al. 2018, 2019a, b; Li and Qian 2018; Liu et al. 2017; Qiao et al. 2018; Tian and Wu 2019; Zhang et al. 2018, 2019; Wei et al. 2017; Wu et al. 2019, 2020). In 2019, the Chinese President, Xi Jinping, delivered his landmark speech at a symposium on ecological protection and highquality development in the Yellow River basin (Xi 2019), and he emphasized the importance of protecting the Yellow River and reviewed the great achievements in Yellow River governance since the founding of the People's Republic of China. Most importantly, he pointed out the important future goals and tasks for ecological protection and high-quality development in the Yellow River basin. The Chinese Loess Plateau is the most important but fragile part of the Yellow River basin. The success of water governance in the Loess Plateau determines the success of water governance in the whole basin.

To achieve a real success in the water governance of the basin, the entire basin should be considered as a whole. What is done in the upper reaches of the river basin will affect what the middle and lower reaches will become, and vice versa. In addition, join efforts from all sectors and departments must be made to achieve the success, which requires 
collaboration not only from domestic researchers and policy makers, but also from international communities. To fully recognize the progress of water governance and environmental protection in the past several decades, the International Symposium on Soil and Water Resources and Ecology in the Loess Plateau was held in Xi' an, China from November 1 to 3,2019 . This conference attracted around 100 delegates who are active researchers and professors from the USA, Canada, South Africa, India and China to share their latest research achievements and illuminating thoughts (Fig. 1). More than 60 abstracts and full manuscripts were received before the conference, and they were peer reviewed. Select submissions on water quality and public health were recommended for inclusion in this special issue.

\section{Papers in this Special Issue}

This issue includes 7 research papers and 2 review papers. The topic of these papers varies from local and regional water contamination and temporal water quality changes to health effects quantification and hydrogeochemical characterization. According to the word cloud generated using the paper titles and abstracts (Fig. 2), the most frequently used word is groundwater, and followed by water, risk, health, $\mathrm{Cr}^{6+}$, quality, study area, China, samples and carcinogenic. These frequently used terms reflect the topics reported in the special issue. The main findings and contributions of these papers are outlined below.

Seeking an efficient approach for risk assessment and decision-making is vital, as the processes of risk assessment and decision-making have great uncertainty. Set pair analysis (SPA) is a novel method of describing and dealing with the uncertainties using the connection number. This approach, which was proposed 30 years ago, has been widely used in earth and environmental sciences, and is becoming more and more important in decision-making for environmental protection, risk evaluation, and disaster prediction. The review paper by Su et al. (2020a) briefly introduced the basic concept of SPA, and then reviewed the development and application of SPA in several disciplinary branches of earth and environmental sciences including engineering geology, hydrology and water resources, meteorology, climatology, and atmospheric environmental science, ecology, and agriculture. The challenges and future prospects of SPA application in earth and environmental sciences were further discussed. The merits of this review paper are that (1) it comprehensively summarized the status of SPA development and its application in different disciplines of earth and environmental sciences, enabling readers to gain a full picture of SPA advantages, and (2) it proposed the future development directions of SPA based on the analysis of challenges that it faces.

The review paper by He et al. (2020) summarized the distribution and hydrochemical characteristics of higharsenic and high-fluoride groundwater in China. The distribution of arsenicosis and fluorosis corresponding to the high-arsenic and high-fluoride groundwater was delineated. Wide distribution of high-arsenic and high-fluoride groundwater contributed to occurrence of arsenicosis and fluorosis in more than half of the provinces/autonomous regions in China. The review paper also reviewed the effective and efficient measures for arsenicosis and fluorosis management including techniques for arsenic and fluoride removal

Fig. 1 Opening ceremony of the conference

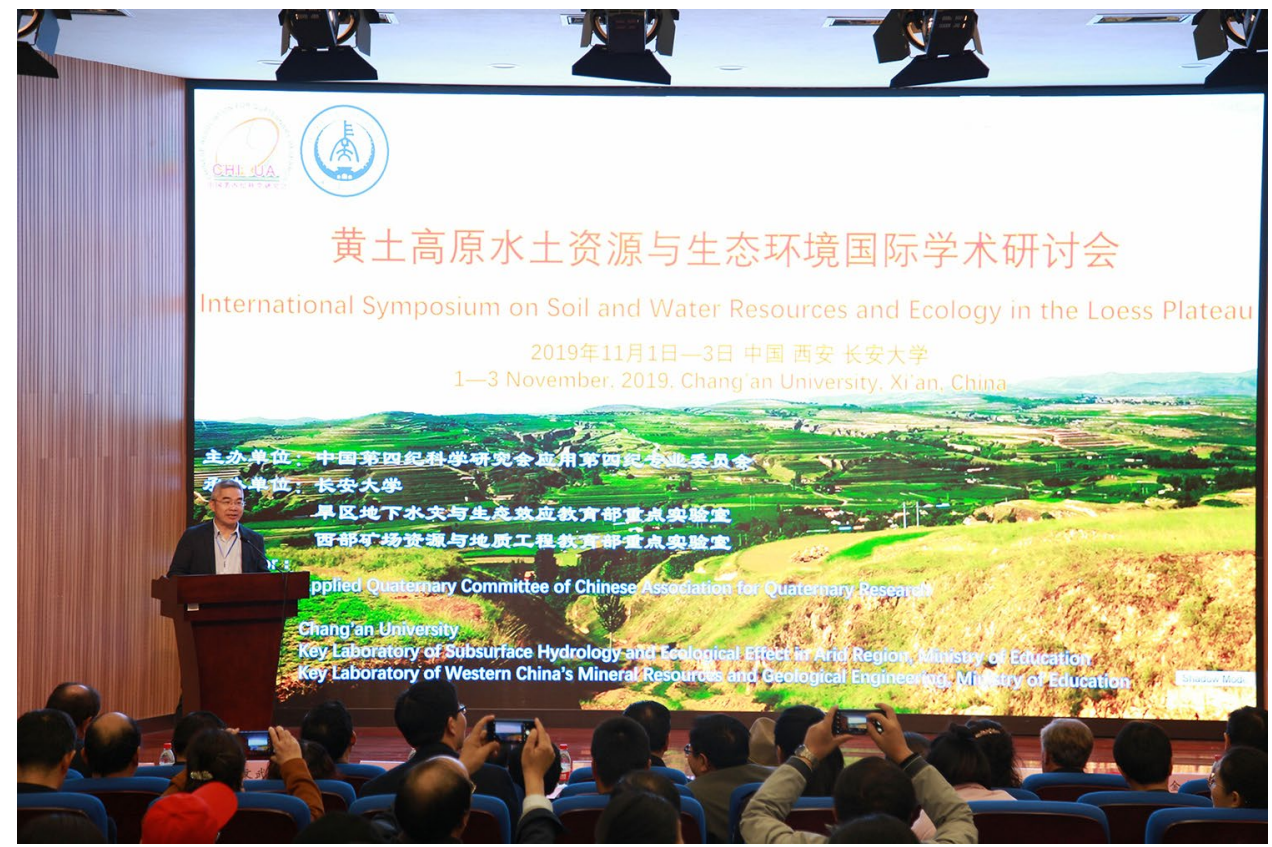


Fig. 2 Word cloud generated using the paper titles and abstracts in this special issue from https://www.wordclouds .com/

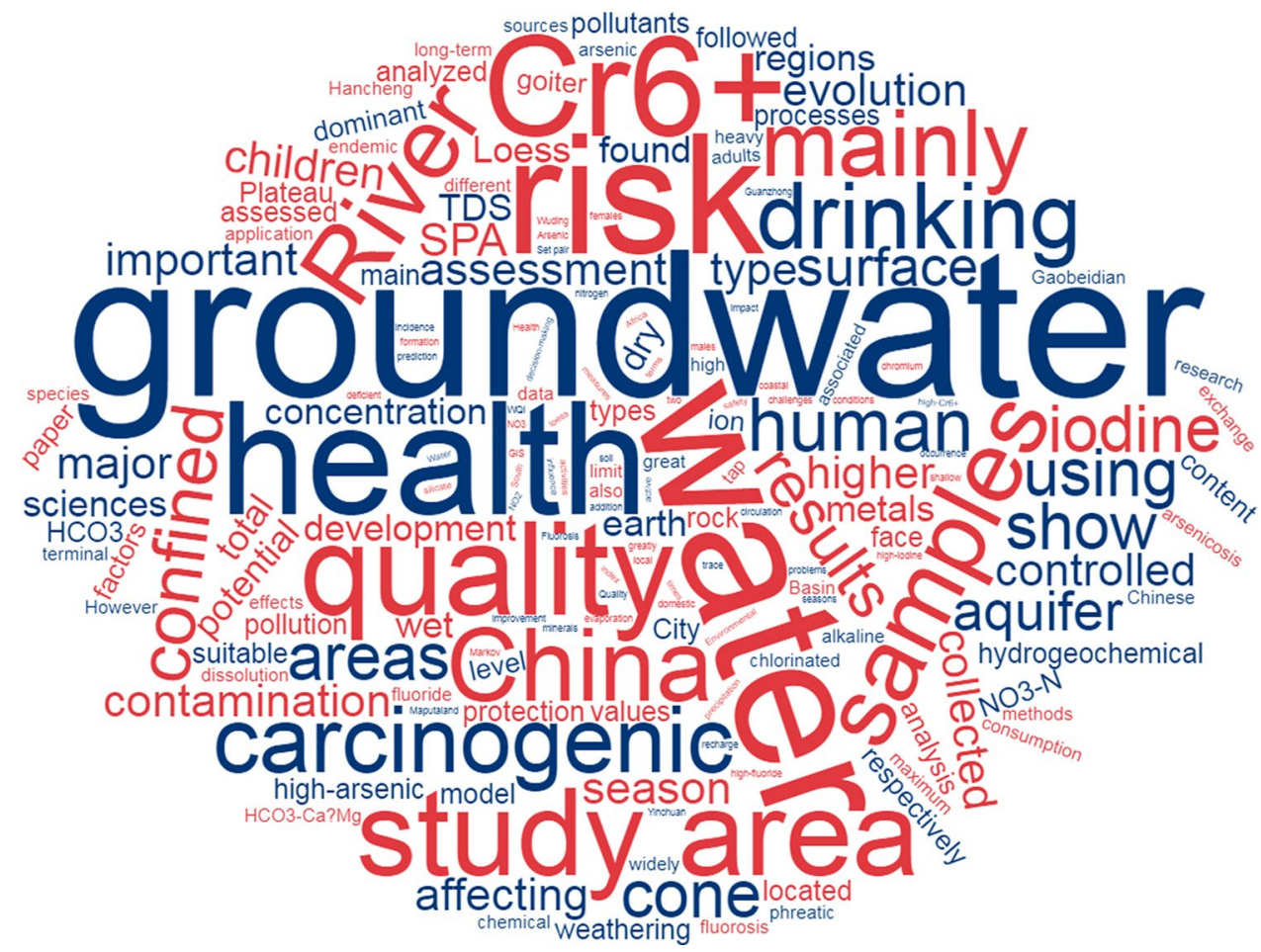

from drinking water, engineering measures for source water quality improvement, and conjunctive use of multiple water sources. Most importantly, this review paper helps people to recognize the situation of high-arsenic and high-fluoride groundwater and associated arsenicosis and fluorosis in China, and thus enables policy makers to implement more effective and efficient measures to reduce the health risk induced from drinking high-arsenic and high-fluoride groundwater.

Similar to fluoride, iodine is also an essential element for human health but becomes toxic in high intake dosage. In the research paper, Duan et al. (2020), taking the Wei River basin as a case study area, investigated the groundwater iodine level and its spatial distribution, and analyzed the hydrochemical characteristics and factors affecting the iodine concentration in groundwater. They used a parabolic equation to describe the relationship of iodine content in groundwater and iodine-disease prevalence in different subsystems of the basin. They concluded that shallow groundwater evaporation-concentration, enriched organic matter biodegradation, competitive adsorption of $\mathrm{HCO}_{3}{ }^{-}$and $\mathrm{I}^{-}$, and stagnant groundwater flow are responsible for highiodine groundwater in the basin.

Trace metals are common contaminants in surface water and groundwater, and they are often toxic to human health due to their bioaccumulation effects. In this special issue, three papers reported trace metal pollution in water. The research paper by $\mathrm{He}$ and $\mathrm{Li}$ (2020) focused at $\mathrm{Cr}^{6+}$ contamination in surface water in the middle of Chinese Loess
Plateau. The $\mathrm{Cr}^{6+}$ concentrations in spring water, Quaternary phreatic water, and soil and rock samples were also analyzed for comparison purpose. The potential sources of $\mathrm{Cr}^{6+}$ were discussed in details and the potential human health risks were assessed to quantify the non-carcinogenic and carcinogenic effects of $\mathrm{Cr}^{6+}$ on human body. They found that the high $\mathrm{Cr}$ content in soil and rock is the primary source of $\mathrm{Cr}^{6+}$ in the surface water, whereas groundwater which contains high $\mathrm{Cr}^{6+}$ concentration is the secondary source. The research paper by Mthembu et al. (2020) took the Maputaland coastal aquifer in South Africa as a case study, and evaluated the hydrogeochemical processes and heavy metal contamination in the groundwater in this aquifer using geostatistical and GIS methods. They performed the health risk quantification, too. They reported heavy metal pollution of $\mathrm{Zn}, \mathrm{Pb}, \mathrm{Al}$ and $\mathrm{Fe}$, which induced health risks to local community. The research paper by Zhou et al. (2020) emphasized the metal-species-weight human health risk assessment of $\mathrm{Cr}^{6+}$, in addition to the distribution and source of carcinogenic and non-carcinogenic pollutants. Their research indicated that the most important chemical species of $\mathrm{Cr}^{6+}$ is $\mathrm{CrO}_{4}{ }^{2-}$, which is the primary contributor to the carcinogenic risk, followed by $\mathrm{CaCrO}_{4}(\mathrm{aq})$ and $\mathrm{HCrO}_{4}{ }^{-}$.

Water shortage crisis in arid regions will inevitably cause extensive groundwater abstraction from aquifers, and this will result in groundwater depression cones. The formation of the groundwater depression cones will affect the groundwater circulation and groundwater quality changes. In the research paper by $\mathrm{Su}$ et al. (2020b), the authors revealed 
the temporal changes of groundwater quality and the affecting factors. They believed that the change in groundwater circulation pattern due to overexploitation is a vital factor affecting the groundwater quality. The authors also proposed a Grey Markov prediction model which incorporated the GM(1,1) model and the Markov chain theory and applied it in the prediction of groundwater salinity within the groundwater depression cone. The delineation and prediction will provide valuable and scientific support for local groundwater quality management.

The suitability of water for beneficial uses is significantly affected by seasonal climate factors. Ji et al. (2020) investigated the seasonal characteristics of drinking water in the Hancheng City of China which was a serious endemic disease-stricken city two decades ago. They concluded that drinking water quality experiences seasonal changes, though over $80 \%$ of the water samples meet standards for drinking and other purposes. Their research also indicated that the health risk is unacceptable in some sampling locations where the overall water quality is, however, acceptable for drinking. This finding emphasized the importance of the health risk assessment as a supplement to traditional water quality assessment. This issue has also been raised by $\mathrm{Wu}$ et al. (2020) who incorporated health risk weighting into traditional water quality assessment.

Zhang et al. (2020) took a local area in the Chinese Loess Plateau as the study region, and reported the groundwater chemistry composition in this area based on physicochemical analysis for 51 groundwater samples. They assessed the non-carcinogenic health risks through ingestion and dermal contact exposure pathways. The main contribution of this research is the application of the criteria importance through inter-criteria correlation (CRITIC) in determining the weights of the water quality parameters. This is an objective weighting method with easy equations. The measures proposed for sustainable groundwater quality management may help local decision makers in seeking effective water quality management techniques.

\section{Collaboration to Make the Water Safer in the Yellow River Basin}

To guarantee the safety of water in the Yellow River basin, more work should be carried out collaboratively. The following five aspects, in my opinion, should be given top priority.

\section{Investigation on Current Water Environment Status in the Yellow River Basin}

Understanding the current water environment status is the basis for securing water safety in the Yellow River basin. Based on field investigation, water sample collection and analysis, a comprehensive investigation of the current status of surface water and groundwater environment in the Yellow River basin should be carried out to ascertain the current status of the surface and groundwater environment in the river basin. Water environmental problems caused by resource development and utilization, such as soil salinization, land subsidence, ground fissures, land desertification, and seawater intrusion should be thoroughly investigated in terms of occurrence, distribution, historical evolution, causes and influencing factors.

\section{Water Quantity Safety in the Yellow River Basin}

Water quantity safety is the basic aspect of water safety in the Yellow River basin. Although the Yellow River is the second largest river in China, many parts of the basin experience arid and semi-arid climate. The total amount of water is inadequate for various purposes and is unevenly distributed in time and space. To properly manage the water resources in the basin, it is vital to understand completely the water cycle in the watershed. Climate change and human activities should be simultaneously considered to quantify the water resources (groundwater, surface water and rainfall). The changing trends of these factors and the mutual transformation between different water resources in the Yellow River basin should be clarified and revealed. The controlling mechanisms and key factors affecting floods, droughts and other water-related disasters must be understood. Finally, a basin scale water resources safety evaluation system should be established.

\section{Water Quality Safety in the Yellow River Basin}

Water quality is directly related to human health. Pollution of surface water, groundwater and soil in the Yellow River basin should be investigated. The evolutionary trend and laws of water and soil pollution should be paid more attention. The key factors and causes of common and emerging pollutants should be quantitatively studied. To do this, the water and soil should be considered as an integrated system. Finally, a basin scale water quality safety evaluation system should also be developed for the Yellow River basin.

\section{Ecological Safety in the Yellow River Basin}

Hydro-ecology is important for high-quality economic development in the Yellow River basin. Based on the research on water quantity and quality of the basin, the main eco-environmental problems in the basin and the key influencing factors should be identified. Numerical models are essential to propose new strategies for solving key water environmental problems such as eutrophication, soil salinization, and land desertification in the basin. It is also vital 
to carry out research on hydro-biogeochemical processes of aquatic ecological evolution, and to develop new technologies for the prevention and control of adverse ecological and environmental impacts.

\section{Synergetic Development of Water Safety and High-Quality Economy in the Yellow River Basin}

General and specific indicators of the basin scale water safety evaluation system should correspond to the goal of ensuring sustainable high-quality basin development. Based on the comprehensive water safety evaluation, a basin scale water safety early warning system which considers natural environmental change and anthropogenic impacts should be set up. This early warning system should consider the economic and social development goals, and should be set up based on solid scientific research.

\section{Final Remarks}

The year 2020 is difficult to the world, as recent outbreak of the novel coronavirus pandemic (COVID-19) strikes almost every country of the world. During the urgent and unprecedented period, most of people stay at home, mourning each death and praying for normal life to come. During this period, I think deeply about what and how hydrogeologists and environmentalists can do to guarantee a safer environment, especially a safer water environment for the world. Learnt from the experience of doctors and governments in combating the COVID-19, I should say collaboration of research from the deep heart of every hydrogeologist and environmentalist may be a promising way. For example, by collaborative research researchers at Cranfield University have found that wastewater testing can be used to estimate the spread of the novel coronavirus more accurately than reagent testing (Cranfield University 2020). A new wastewaterbased epidemiology (WBE) method for detecting the novel coronavirus is being developed. This method can effectively and quickly predict the possibility of potential novel coronaviruses spread by identifying biomarkers from the feces and urine of disease carriers entering the drainage system (Mao et al. 2020). The world needs collaboration to become better and the hydrogeologists need collaboration to make water safer. There are so many challenges in the water community, all of which cannot be solved by a single person. Only collaboration can finally find ways to overcome these challenges.

Acknowledgements I am highly grateful for the support rendered by the Editor in Chief, Prof. Andrew Meharg who helped me and answered all my questions in a timely manner. As I said many times, the entire editorial team of Exposure and Health is an efficient and outstanding team, thanks to which the special issue can be published on time. The reviewers are critical elements for the successful release of the special issue. Their voluntary but excellent work is sincerely acknowledged. Prof. Wanfang Zhou from the ZeoEnvironmental, USA is acknowledged for his editorial editing on the early version of the manuscript. Finally, financial support has been received from the National Natural Science Foundation of China (41761144059), the Fundamental Research Funds for the Central Universities of CHD (300102299301), the Fok Ying Tong Education Foundation (161098), the China Postdoctoral Science Foundation (2015M580804, 2016M590911, 2016T090878 and 2017T100719), the Shaanxi Postdoctoral Science Foundation (2015BSHTDZZ09 and 2016BSHTDZZ03) and the Ten Thousand Talent Program (W03070125), which should be acknowledged.

\section{Compliance with Ethical Standards}

Conflict of interest The author declares that they have no conflict of interest.

\section{References}

Chellaney B (2013) Water, peace, and war: confronting the global water crisis. Rowman \& Littlefield Publishers, Lanham, p 400

Cranfield University (2020) Wastewater test could provide early warning of COVID-19. Available at https://www.cranfield.ac.uk/press/ news-2020/wastewater-test-could-provide-early-warning-of-covid -19 (accessed 11 Apr 2020)

Duan L, Wang W, Sun Y, Zhang C, Sun Y (2020) Hydrogeochemical characteristics and health effects of iodine in groundwater in Wei River Basin. Expo Health. https://doi.org/10.1007/s12403-02000348-7

Han D, Currell MJ, Cao G (2016) Deep challenges for China's war on water pollution. Environ Pollut 218:1222-1233. https://doi. org/10.1016/j.envpol.2016.08.078

He S, Wu J (2019a) Hydrogeochemical characteristics, groundwater quality and health risks from hexavalent chromium and nitrate in groundwater of Huanhe Formation in Wuqi County, northwest China. Expo Health 11(2):125-137. https://doi.org/10.1007/s1240 3-018-0289-7

He S, Wu J (2019b) Relationships of groundwater quality and associated health risks with land use/land cover patterns: a case study in a loess area, northwest China. Hum Ecol Risk Assess 25(12):354-373. https://doi.org/10.1080/10807039.2019.1570463

He X, Li P (2020) Surface water pollution in the middle Chinese Loess Plateau with special focus on hexavalent chromium $\left(\mathrm{Cr}^{6+}\right)$ : occurrence, sources and health risks. Expo Health. https://doi. org/10.1007/s12403-020-00344-x

He X, Wu J, He S (2019) Hydrochemical characteristics and quality evaluation of groundwater in terms of health risks in Luohe aquifer in Wuqi County of the Chinese Loess Plateau, northwest China. Hum Ecol Risk Assess 25(1-2):32-51. https://doi. org/10.1080/10807039.2018.1531693

He X, Li P, Ji Y, Wang Y, Su Z, Elumalai V (2020) Groundwater arsenic and fluoride and associated arsenicosis and fluorosis in China: occurrence, distribution and management. Expo Health. https:// doi.org/10.1007/s12403-020-00347-8

Ji Y, Wu J, Wang Y, Elumalai V, Subramani T (2020) Seasonal variation of drinking water quality and human health risk assessment in Hancheng City of Guanzhong Plain China. Expo Health. https ://doi.org/10.1007/s12403-020-00357-6

Li P, Qian H (2018) Water in Loess. In: Meyers RA (ed) Encyclopedia of sustainability science and technology. Springer, New York, pp 1-17. https://doi.org/10.1007/978-1-4939-2493-6_968-1 
Li P, Wu J (2019a) Drinking water quality and public health. Expo Health 11(2):73-79. https://doi.org/10.1007/s12403-019-00299-8

Li P, Wu J (2019b) Sustainable living with risks: meeting the challenges. Hum Ecol Risk Assess 25(1-2):1-10. https://doi. org/10.1080/10807039.2019.1584030

Li P, He S, Yang N, Xiang G (2018) Groundwater quality assessment for domestic and agricultural purposes in Yan'an City, northwest China: implications to sustainable groundwater quality management on the Loess Plateau. Environ Earth Sci 77(23):775. https:// doi.org/10.1007/s12665-018-7968-3

Li P, He X, Guo W (2019a) Spatial groundwater quality and potential health risks due to nitrate ingestion through drinking water: a case study in Yan'an City on the Loess Plateau of northwest China. Hum Ecol Risk Assess 25(1-2):11-31. https://doi. org/10.1080/10807039.2018.1553612

Li P, He X, Li Y, Xiang G (2019b) Occurrence and health implication of fluoride in groundwater of loess aquifer in the Chinese Loess Plateau: a case study of Tongchuan, northwest China. Expo Health 11(2):95-107. https://doi.org/10.1007/s12403-018-0278-x

Liu Z, Li L, Wang L, Wang Q, Li Q (2017) Hydrological situation of a typical watershed in the Loess Tableland Area of China over the past 30 years. Environ Earth Sci 76:577. https://doi.org/10.1007/ s12665-017-6915-z

Lowe R, Silvester E (2014) Water shortages threaten global security. International Bar Association Global Insight 68(4):42

Mao K, Zhang H, Yang Z (2020) Can a paper-based device trace COVID-19 sources with wastewater-based epidemiology? Environ Sci Technol 54:3733-3735. https://doi.org/10.1021/acs.est.0c011 74

Mthembu PP, Elumalai V, Karthikeyan B, Li P (2020) Hydrogeochemical processes and heavy metal contamination in groundwater: a case study on health risk assessment of Maputaland coastal aquifer, South Africa. Expo Health. https://doi.org/10.1007/s1240 3-020-00369-2

Oki T, Kanae S (2006) Global hydrological cycles and world water resources. Science 313(5790):1068-1072. https://doi.org/10.1126/ science. 1128845

Qiao X, Li X, Guo Y, Ma S (2018) In-situ experimental research on water scouring of loess slopes. Environ Earth Sci 77:417. https:// doi.org/10.1007/s12665-018-7593-1

Su F, Li P, He X, Elumalai V (2020a) Set pair analysis in earth and environmental sciences: development, challenges, and future prospects. Expo Health. https://doi.org/10.1007/s12403-020-00368-3

Su Z, Wu J, He X, Elumalai V (2020b) Temporal changes of groundwater quality within the groundwater depression cone and prediction of confined groundwater salinity using Grey Markov model in Yinchuan area of northwest China. Expo Health. https://doi. org/10.1007/s12403-020-00355-8
Tian R, Wu J (2019) Groundwater quality appraisal by improved set pair analysis with game theory weightage and health risk estimation of contaminants for Xuecha drinking water source in a loess area in Northwest China. Hum Ecol Risk Assess 25(1-2):132157. https://doi.org/10.1080/10807039.2019.1573035

Wei Y, Fan W, Wang W, Deng L (2017) Identification of nitrate pollution sources of groundwater and analysis of potential pollution paths in loess regions: a case study in Tongchuan region, China. Environ Earth Sci 76:423. https://doi.org/10.1007/s1266 5-017-6756-9

Wu J, Zhou H, He S, Zhang Y (2019) Comprehensive understanding of groundwater quality for domestic and agricultural purposes in terms of health risks in a coal mine area of the Ordos basin, north of the Chinese Loess Plateau. Environ Earth Sci 78(15):446. https ://doi.org/10.1007/s12665-019-8471-1

Wu J, Zhang Y, Zhou H (2020) Groundwater chemistry and groundwater quality index incorporating health risk weighting in Dingbian County, Ordos basin of northwest China. Geochemistry. https:// doi.org/10.1016/j.chemer.2020.125607

Xi J (2019) Speech at the symposium on ecological protection and high-quality development in the Yellow River Basin. Water Conservancy Construction and Management 31(12):1-3. https://doi. org/10.16616/j.cnki.11-4446/TV.2019.11.01 (in Chinese)

Zhang Q, Xu P, Qian H (2020) Groundwater quality assessment using improved water quality index (WQI) and human health risk (HHR) evaluation in a semi-arid region of northwest China. Expo Health. https://doi.org/10.1007/s12403-020-00345-w

Zhang Y, Wu J, Xu B (2018) Human health risk assessment of groundwater nitrogen pollution in Jinghui canal irrigation area of the loess region, northwest China. Environ Earth Sci 77(7):273. https ://doi.org/10.1007/s12665-018-7456-9

Zhang Y, Xu B, Guo Z, Han J, Li H, Jin L, Chen F, Xiong Y (2019) Human health risk assessment of groundwater arsenic contamination in Jinghui irrigation district, China. J Environ Manage 237:163-169. https://doi.org/10.1016/j.jenvman.2019.02.067

Zhou Y, Ning J, Li L, Wei A, Liu Z (2020) Health risk assessment of groundwater in Gaobeidian, north China: distribution, source, and chemical species of the main contaminants. Expo Health. https:// doi.org/10.1007/s12403-020-00365-6

Publisher's Note Springer Nature remains neutral with regard to jurisdictional claims in published maps and institutional affiliations. 